\title{
Hydrogenated Microstructure and Its Hydrogenation Properties: A Density Functional Theory Study
}

\author{
M. Abdus Salam, Bawadi Abdullah, and Suriati Sufian \\ Chemical Engineering Department, Universiti Teknologi PETRONAS, Bandar Seri Iskandar, 31750 Tronoh, \\ Perak Darul Ridzuan, Malaysia \\ Correspondence should be addressed to Bawadi Abdullah; bawadi_abdullah@petronas.com.my
}

Received 24 June 2014; Revised 12 August 2014; Accepted 12 August 2014; Published 13 October 2014

Academic Editor: Fathallah Karimzadeh

Copyright (C) 2014 M. Abdus Salam et al. This is an open access article distributed under the Creative Commons Attribution License, which permits unrestricted use, distribution, and reproduction in any medium, provided the original work is properly cited.

\begin{abstract}
The relationship between microstructure and hydrogenation properties of the mixed metals has been investigated via different spectroscopic techniques and the density functional theory (DFT). FESEM and TEM analyses demonstrated the nano-grains of $\mathrm{Mg}_{2} \mathrm{NiH}_{4}$ and $\mathrm{MgH}_{2}$ on the hydrogenated microstructure of the adsorbents that were confirmed by using XPS analysis technique. SAED pattern of hydrogenated metals attributed the polycrystalline nature of mixed metals and ensured the hydrogenation to $\mathrm{Mg}_{2} \mathrm{NiH}_{4}$ and $\mathrm{MgH}_{2}$ compounds. Flower-like rough surface of mixed metals showed high hydrogenation capacity. The density functional theory (DFT) predicted hydrogenation properties; enthalpy and entropy changes of hydrogenated microstructure of $\mathrm{MgH}_{2}$ and $\mathrm{Mg}_{2} \mathrm{NiH}_{4}$ are $-62.90 \mathrm{~kJ} / \mathrm{mol},-158 \mathrm{~J} / \mathrm{mol} \cdot \mathrm{K}$ and $-52.78 \mathrm{~kJ} / \mathrm{mol},-166 \mathrm{~J} / \mathrm{mol} \cdot \mathrm{K}$, respectively. The investigation corresponds to the hydrogen adsorption feasibility, reversible range hydrogenation thermodynamics, and hydrogen desorption energy of $54.72 \mathrm{~kJ} / \mathrm{mol}$. DFT predicted IR band for $\mathrm{MgH}_{2}$ and $\mathrm{Mg}_{2} \mathrm{NiH}_{4}$ attributed hydrogen saturation on metal surfaces.
\end{abstract}

\section{Introduction}

The global energy demand is increasing in parallel with the population growth, economic expansion, and increasing demand of mobility. Hydrogen is known as an abundant source of clean energy carrier. There are few ways to utilize the hydrogen as source of energy. Metal-hydrogen system demonstrated the best option for hydrogenated system due to the higher hydrogen density in the system than liquid or gas phases [1]. Higher hydrogen density, reversible thermodynamics, low desorption temperature, and low production cost are vital requirements for metal-hydrogen system. Magnesium based mixed oxides are potential candidate to meet the above requirements [2]. The drawbacks of hydrogenation in magnesium based alloys are [3] stability of the $\mathrm{MgH}_{2}$ phase, formation of a surface oxide(s), slow dissociation of hydrogen at the metal surface, and slow diffusion of hydrogen through $\mathrm{MgH}_{2}$ grain. The problems can be overcome by developing microstructure that reduces the diffusion path and creates enough active site for dissociation $[2,3]$. Grain boundaries provide active nucleation sites in hydride formation and decomposition of the hydride phases. Reduction of grain size or crystalline size of the materials enhances the hydrogen diffusion that moves faster along the grain boundaries.

Different strategies have been investigated to achieve reversible range hydrogen adsorption thermodynamics and kinetics. Homogenous and ultrafine microstructure of adsorbent is one of the important techniques to enhance the hydrogenation capacity and to achieve favorable thermodynamics [4]. Second technique is considered as addition of catalytic elements or rear earth metals or transitional metals to adsorbent. Transition metal oxides are an important catalyst in Mg-based adsorbent to get high hydrogenation capacity [5]. $\mathrm{Mg}_{2} \mathrm{Ni}$ alloy demonstrates higher hydrogenation kinetics and desorption at lower temperature because of the effect of transitional metal such as nickel [6]. Coprecipitation under low supersaturation synthesis method produces homogenously metals dispersed hydrotalcite [7]. The materials show high catalytic activity for hydrogenation and flexible to form different microstructure by optimizing the preparation conditions and metals. 
Many DFT based studies have been reported for magnesium based hydrogen storage adsorbents $[8,9]$. The density functional theory (DFT) based QM (quantum mechanical) descriptors describe adsorption properties such as adsorption thermodynamics and kinetics, interaction energy, and adsorption and desorption energy that support to observe the hydrogenation mechanism and properties [10] of the materials. Noncovalent week interaction energies can be determined precisely using M05-2X functional [11].

Microstructure influences hydrogenation or dehydrogenation properties strongly [12]. It is a novel initiative to make a clarification of hydrogenation on reduced mixed metal oxides microstructure via experimental and theoretical way. In this study, hydrogenated microstructure is investigated through electron microscopic techniques and studied hydrogenation/dehydrogenation properties using the density functional theory (DFT) to establish a relation between hydrogenation and microstructure of the material.

\section{Experimental Section}

2.1. Experimentation. Hydrotalcite based mixed oxides containing $\mathrm{Mg}, \mathrm{Ni}$, and $\mathrm{Al}$ were prepared by using the conventional coprecipitation method under low supersaturation method as described elsewhere [13]. The synthesis $\mathrm{pH}$ of 10 was optimized to get the flower-like rough surface. Optimized synthesis temperature of $55^{\circ} \mathrm{C}$ and molar ratio of metals were used as $\mathrm{Mg}: \mathrm{Ni}: \mathrm{Al}=2: 1: 1$. The fresh developed materials were calcined at $650^{\circ} \mathrm{C}$ for two hours to convert the mixed metals oxides.

The hydrogen adsorption equilibrium of mixed oxide was measured at the conditions of temperature $\left(30^{\circ} \mathrm{C}\right)$ and pressure (0-760 $\mathrm{mmHg}$ ) using a micrometrics ASAP 2020C sorptometer. A $20 \mathrm{mg}$ sample was degassed using both preparation port and sample port. It was reduced by $\mathrm{H}_{2}$ gas purging at $20 \mathrm{~mL} / \mathrm{min}$, with a temperature ramping of $10^{\circ} \mathrm{C} / \mathrm{min}$ up to $850^{\circ} \mathrm{C}$, which further cool down to $30^{\circ} \mathrm{C}$ under vacuum condition. $99.99 \%$ hydrogen gas was used to inlet the adsorption unit. Hydrogen adsorption isotherm analyses were carried out at $30^{\circ} \mathrm{C}$ with a pressure of $0-$ $760 \mathrm{mmHg}$. Reversible adsorption isotherms were collected by performing a 30-minute evacuation at the experiment temperature following the total adsorption isotherm.

The microstructure of hydrogenated mixed metals was analyzed using field emission scanning electron microscopy (FESEM) technique. CARL Zeiss Supra 55VP FESEM instrument equipped with the Oxford INCA 400 EDX microanalysis system with an operating voltage in the range of $0.1-30 \mathrm{kV}$ was used. The system was vacuumed before analyses and the mixed metals were introduced in the sample grid.

The microstructure of hydrogenated adsorbent was investigated using a CARL Zeiss LIBRA 200FE, TEM using ultrasonically dispersed samples in isopropanol. Selected area electron diffraction (SAED) patterns were collected for hydrogenated single sheet. The diffraction rings of SAED pattern were indexed using the diameter of the rings and calculating the ratio of those diameters $\left(r_{n} / r_{1}\right)$ for different phases.
The surface composition of the hydrogenated adsorbent was analysed by X-ray photoelectron spectroscopy (XPS) using a Perkin Elmer 1257 model, operating at a base pressure of $3.5 \times 10^{-6} \mathrm{~Pa}$ at $300 \mathrm{~K}$ with a nonmonochromatized Al-K $\alpha$ line at $1486.6 \mathrm{eV}$ and a hemispherical sector analyzer.

2.2. Computational Methods. The hydrogenated clusters or hydrides were optimized (geometrically) using M05-2X functional [11] along with the $6-311+G(d, p)$ basis set [14]. All computations were performed using Gaussian 09W computational program package [15]. Frequency calculations were conducted on optimized geometries of clusters to ensure the minima on potential energy surface (PES). Cluster descriptors such as chemical potential [16], strength of charge transfer [17], and electrophilicity [18] were calculated by using finite approximation. Energy of interaction $\left(\Delta E_{i}\right)$, hydrogenation energy $\left(\Delta E_{\mathrm{Hyd}}\right)$, and average desorption energy $\left(\Delta E_{\mathrm{DE}}\right)$ [19] per hydrogen molecule were calculated using different equation as stated by Salam et al. [10]. Thermodynamics parameters such as heat of reaction and free energies have been calculated using computed energies of reactants and products [20]; The IR spectrum of hydride clusters was generated using computational software (Gaussian 09W) via frequency calculation.

\section{Results and Discussion}

\subsection{Experimental Analyses}

3.1.1. Hydrogen Adsorption Mechanism. Isothermal adsorption analysis predicted the hydrogen storage capacity of $3.9 \mathrm{wt} \%$ hydrogen of the reduced mixed metals oxides containing magnesium, nickel, and aluminium [13]. A hydrogenation mechanism and causes of hydrogenation can be explained by pointing out different factors.

The surface of s-orbital electron and d-orbital electrons of atom plays a key role in the hydrogen dissociation on the metals surface. $\mathrm{H}_{2}$ molecules come to the metals surface in the hydrogenation process. The molecular orbitals of hydrogen $\left(1 s^{2}\right)$ start to overlap on the metals surface sorbital electrons. According to the Pauli Exclusion Principle, hydrogen s-orbital electron repels due to the fully occupied valence electron of metals ( $\mathrm{Mg}: 1 \mathrm{~s}^{2} 2 \mathrm{~s}^{2} 2 \mathrm{p}^{6} 3 \mathrm{~s}^{2}$ ), resulting in the energy barrier. The metals with d-orbital electrons contribute in the dissociation of $\mathrm{H}_{2} \cdot \mathrm{H}_{2}$ comes closer to the metal surface; the charge transfers from the $\mathrm{H}_{2}$ s-orbital to the $\mathrm{d}$ orbital of metal (Ni (28): $1 s^{2} 2 s^{2} 2 p^{6} 3 s^{2} 3 p^{6} 3 d^{8} 4 s^{2}$ ) surface and simultaneously a back-donation of charge from the surface d-orbital to the $\mathrm{H}_{2}$ antibonding state. Thus, the interaction between d-orbital of nickel and s-orbital of $\mathrm{H}_{2}$ enhances the $\mathrm{H}_{2}$ dissociation on the adsorbent surface with a small energy barrier. The main group element of aluminum ( $\mathrm{Al}(13)$ : $1 s^{2} 2 s^{2} 2 p^{6} 3 s^{2} 3 p^{1}$ ) valence electron is three (3).

The electron affinity of $\mathrm{Al}$ is $-44 \mathrm{~kJ} / \mathrm{mol}$ and shows low affinity to $\mathrm{H}$. Since the $\mathrm{p}$-state of $\mathrm{Al}$ can accommodate electron more, it competes with $\mathrm{H}$ (hydrogen) for the valence electrons of $\mathrm{Mg}\left(\mathrm{Mg}(12): 1 s^{2} 2 s^{2} 2 \mathrm{p}^{6} 3 \mathrm{~s}^{2}\right)$. The electron affinities of magnesium and hydrogen are $21 \mathrm{~kJ} / \mathrm{mol}$ and $-74 \mathrm{~kJ} / \mathrm{mol}$. 


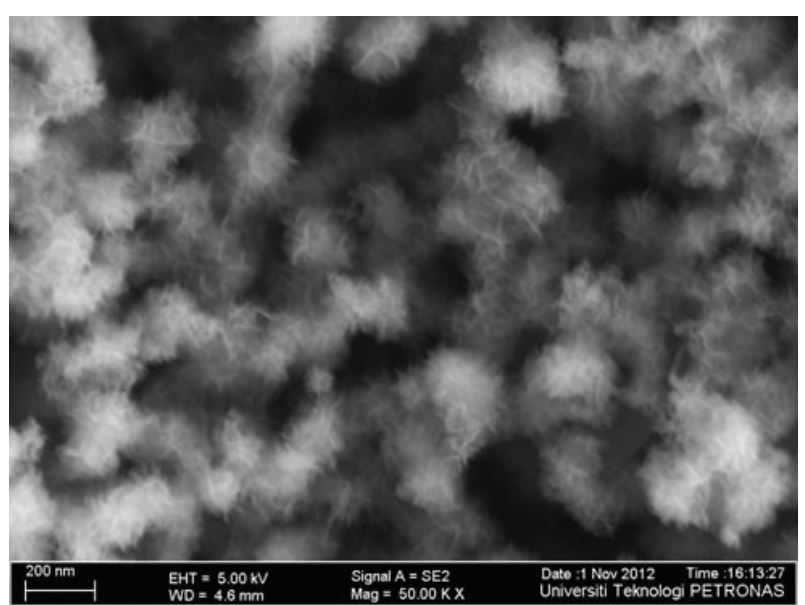

FIGURE 1: Microstructure of synthesized mixed oxides.

Therefore, hydrogen binds with weak interaction (lower bonding strength) with the $\mathrm{Mg}$ or $\mathrm{Mg}_{2} \mathrm{Ni}$ and forms reversible hydride of $\mathrm{Mg}_{2} \mathrm{NiH}_{4}$ and $\mathrm{MgH}_{2}$. Aluminum also works as cofactor to heat transfer quickly for better decomposition of hydrides from microstructure.

3.1.2. Microstructure of Mixed Metals Oxides. Figure 1 shows the flower-like rough microstructure of the mixed metals oxides. At $\mathrm{pH}=10$, cations $\mathrm{Al}^{3+}, \mathrm{Ni}^{2+}$, and $\mathrm{Mg}^{2+}$ precipitated simultaneously as $\mathrm{Mg}(\mathrm{OH})_{2}, \mathrm{Ni}(\mathrm{OH})_{2}$, and $\mathrm{Al}(\mathrm{OH})_{3}$ that immediately converted to the $\mathrm{Mg}(\mathrm{Ni}) \mathrm{Al}-\mathrm{CO}_{3}$ structure. The flower-like particle of material can be considered as composed of hexagonal nanosheets which are dependent on isoelectric point of metal hydroxides. The nanosheet or nanoflakes were observed via high resolution FESEM image (not shown here). The nanosheets seem to be flexible and can be wrinkled during precipitation at experimental conditions that help to form flower-like particle. If $\mathrm{pH}=$ IEP (isoelectric point), the $\mathrm{MgAl}-\mathrm{CO}_{3}$ nanoparticle is in net zero point charge and the formation of hydrotalcite becomes slow along the 001 plane. In the initial stage, the interfacial energy between the nuclei and the support is low and metal hydroxide nuclei are grown within their 001 plane. Since the reaction is continuous (during synthesis), the subsequent nucleation is grown preferentially on the surface of the previously grown particles. Thus, the growth of the primary nanoparticles turns to flower-like morphology. After calcination, the materials retained its shape. The reason is that the trivalent cations of $\mathrm{Al}^{3+}$ substitute the divalent cations of $\mathrm{Mg}^{2+}, \mathrm{Ni}^{2+}$ to the brucite sheets and converted to periclase-like $\mathrm{Mg}-\mathrm{Al}-\mathrm{O}$ or $\mathrm{Mg}(\mathrm{Ni}) \mathrm{Al}-\mathrm{O}$ solid solution. Thus, the brucite-like shape of the crystal remained in the resulting $\mathrm{Mg} / \mathrm{Ni}-\mathrm{Al}-\mathrm{O}$ structure. Different synthesis conditions demonstrate different microstructure for this metals combination.

EDX analysis demonstrated the elemental composition of microstructure of the mixed metals oxides in Figure 2. Since the material is in mixed oxides form, it shows high amount of oxygen (30 wt\%). Magnesium, nickel, and aluminium maintain the ratio (based on wt\%) of $2: 1: 1$.

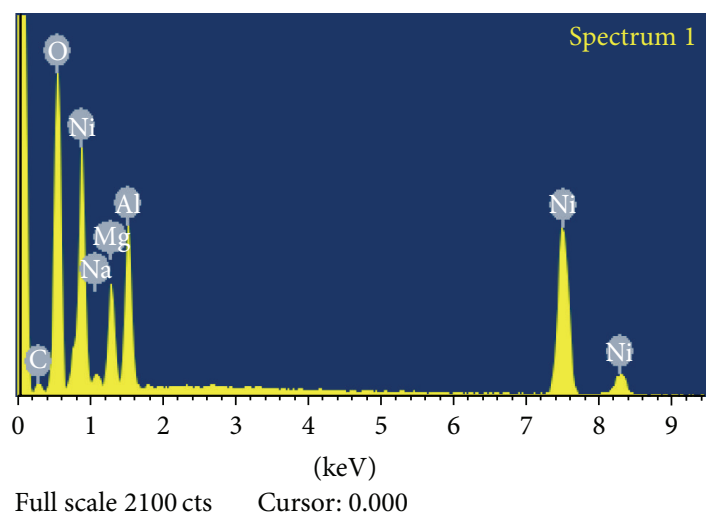

FIgURE 2: Elemental composition of the material microstructure.

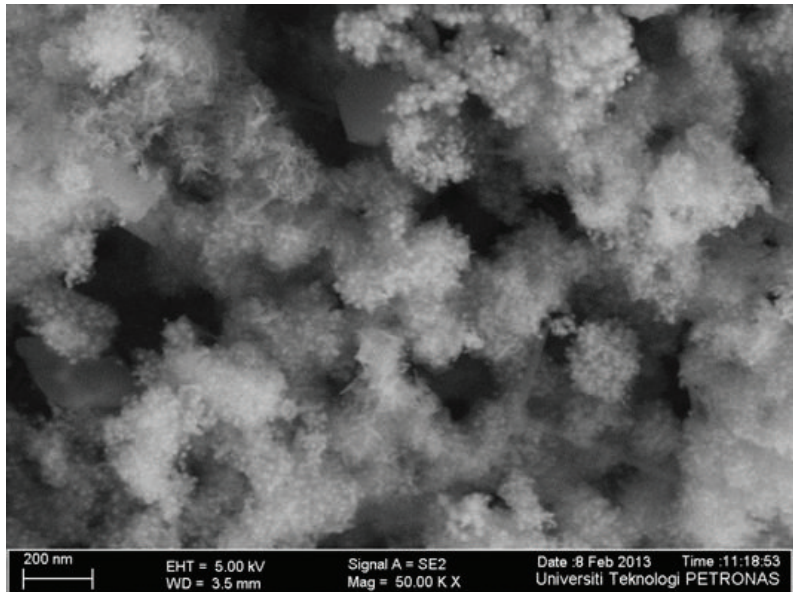

Figure 3: Microstructure of hydrogenated complex.

3.1.3. Microstructure of Hydrogenated Mixed Metals. Microstructure of the hydrogenated mixed metals is shown in Figure 3. Hydrogen makes bond with every flake of the flower-like particle, thus forming very small grains. Therefore, well-defined grains attribute the faster hydrogenation and high hydrogen capacity of $\mathrm{Mg}_{2} \mathrm{NiH}_{4}$ [6]. The size range of hydrogenated grains is in $20-40 \mathrm{~nm}$ and synthesized adsorbent form 100-180 nm sizes of flower-like particles in optimized experimental conditions. The rough surfaces of flower-like particles offer active sites to attach hydrogen to each flake and enhance the hydrogenation capacity. The hydride nucleation takes place at the end of flakes including grain boundaries. The hydrogenation rate and hydrogen capacity of material increase rapidly with increasing active site and for the homogenous distribution of catalytic metals of nickel on microstructure. The surface with hexagonal particle demonstrates less hydrogenation in same conditions [13] which is due to the shortage of active site of materials. The $\beta$ $\mathrm{MgH}_{2}$ is formed at ambient temperature as a rutile structure as observed by Zachariasen et al., [21].

The TEM image of the adsorbent (Figure 4) shows the flower-like particle which is also observed by FESEM image in Figure 1(a). The newly formed irregular shape of grain 


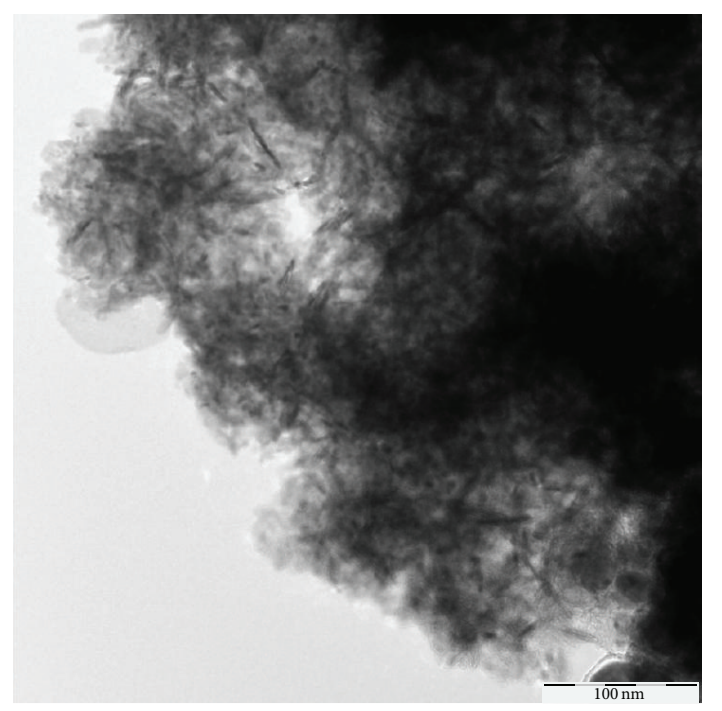

FIgURE 4: TEM of hydrogenated complex.

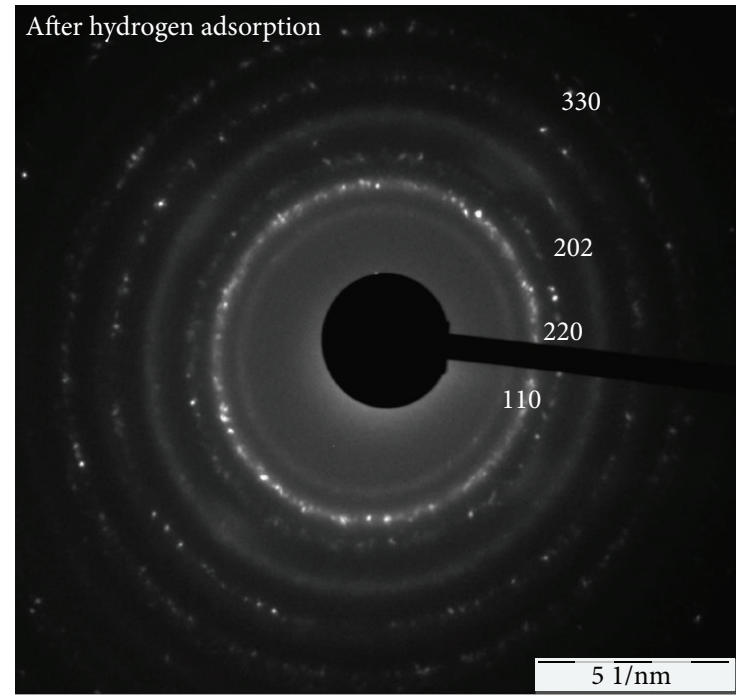

FIGURE 5: SAED pattern of hydrogenated complex.

adjacent to the flakes of the particle is due to the formation of different phases of hydride at ambient conditions. The adsorbent shows the well-shaped diffusion path and grain boundaries. SAED (selected area electron diffraction) pattern of hydrogenated metals is shown in Figure 5 which attributes the crystal planes of (110), (202), (220), and (330) and corresponding the presence of $\mathrm{MgH}_{2}, \mathrm{Mg}_{2} \mathrm{NiH}_{4}$, and $\mathrm{MgO}$ in crystal. Similar planes of SAED pattern were observed by Zou et al., [22]. Different metals' combination creates a different microstructure due to the structural change and balance band of the adsorbent that influence the hydrogenation on material surface.

3.1.4. Hydrogenated Phases of Adsorbent. Hydrogenated microstructure was analyzed by XPS techniques to confirm the hydride phases and for further studies. Binding energy of hydrides is higher than elemental species, because metals loss their electron in forming hydrides [23]. X-ray photoelectron spectra of $\mathrm{Mg}(1 \mathrm{~s}), \mathrm{Mg}(2 \mathrm{p})$, and $\mathrm{Ni}(2 \mathrm{p})$ are shown in previous investigation [6]. Hydride phases of $\mathrm{MgH}_{2}$ and $\mathrm{Mg}_{2} \mathrm{NiH}_{4}$ can be observed by measuring their higher binding energies as compared to corresponding elements. Combination of magnesium and nickel modifies the electronic structure to $\mathrm{Mg}_{2} \mathrm{NiH}_{4}$ that enhances the hydrogenation. $\mathrm{Mg}$ and $\mathrm{Ni}$ change the structure that reduces the formation of $\mathrm{Mg}(\mathrm{OH})_{2}$ and increases hydrogenation [24].

3.2. Microstructure Analysis Using DFT. The study highlights the hydrogenation properties of hydrogenated microstructure or hydrogenated phases of $\mathrm{MgH}_{2}$ and $\mathrm{Mg}_{2} \mathrm{NiH}_{4}$ that were confirmed by experimental analyses in this study. The geometry of clusters has been optimized successfully and shown in Figure 6 . To observe the variation of hydrogenation properties, Mg- $\left(\mathrm{H}_{2}\right)_{2}$ is included along with two hydride clusters of $\mathrm{MgH}_{2}$ and $\mathrm{Mg}_{2} \mathrm{NiH}_{4}$. Frequency analyses predict their minima on potential energy surface (PES) and free from imaginary frequencies (Figures 7 and 8). The electronic properties of clusters and feasibility of their application are discussed next.

Total electronic energy and thermodynamical descriptors, hardness, electronegativity, and electrophilicity of hydrides are calculated and shown in Table 1. The increasing trend of electronic energy of $\mathrm{Mg}-\left(\mathrm{H}_{2}\right)_{n}$ based on gradual number of captured hydrogen corresponds hydrogenation on metals surface. Chemical hardness determines the clusters strength to donate/accept the charges and the chemical potential represents the electron shifting trend from systems or clusters. Minimum electrophilicity principle (MEP) and maximum hardness principle (MHP) attribute the $\mathrm{Mg}_{2} \mathrm{NiH}_{4}$ hydride which is more stable than $\mathrm{Mg}-\left(\mathrm{H}_{2}\right)_{n}$ [25].

The IR studies on hydrogenated clusters provide two significant properties. IR spectrum of hydrogenated clusters shows that they are free from imaginary frequency indicating that the minima on potential energy surface (PES). Secondly, it confirms the hydrogen saturation on metal surface. IR peaks in the frequency region of $400-2000 \mathrm{~cm}^{-1}$ confirm the hydrogen saturation on metal surface of $\mathrm{Mg}$ and $\mathrm{Ni}$ containing clusters. Linear structure of $\mathrm{MgH}_{2}$ was produced in the method of UM052X/6-311+G(d,p) calculation and a strong $\mathrm{Mg}-\mathrm{H}$ antisymmetric stretching frequency mode at $1637 \mathrm{~cm}^{-1}$ and a bending frequency mode at $460 \mathrm{~cm}^{-1}$ is observed. The inclusion of ground-state $\mathrm{Mg}\left(3 \mathrm{~s}^{1}, \mathrm{~S}\right)$ into hydrogen experiences large energy barrier. Therefore, $\mathrm{Mg}$ atom exited to the electronic state of $\left(3 s 3 p,{ }^{1} \mathrm{P}\right)$ to overcome the energy barrier and insert into hydrogen. The vibration between 1000 and $1200 \mathrm{~cm}^{-1}$ is because of the bridge of $\mathrm{Mg}$ $\mathrm{H}-\mathrm{Mg}$ bond stretching. Outcome of calculation suggests that stronger interaction for $\mathrm{H}-\mathrm{Mg}-\mathrm{H}$ with hydrogen on metal surface is due to the strong $\mathrm{H}-\mathrm{H}$ stretching modes induced by $\mathrm{MgH}_{2}$. The band at $1645 \mathrm{~cm}^{-1}$ is symmetrical stretching mode of $\mathrm{H}-\mathrm{Ni}-\mathrm{H}$. Intermetallic ternary hydride $\mathrm{Mg}_{2} \mathrm{Ni}-\left(\mathrm{H}_{2}\right)_{2}$ $\left(=\mathrm{Mg}_{2} \mathrm{NiH}_{4}\right)$ displayed the vibrational band (Figure 8) at $222,528,650,7685,1100$, and $2030 \mathrm{~cm}^{-1}$ which includes the common band of Ni- $\left(\mathrm{H}_{2}\right)_{n}$; here, $n=1$ or 2 [26]. 


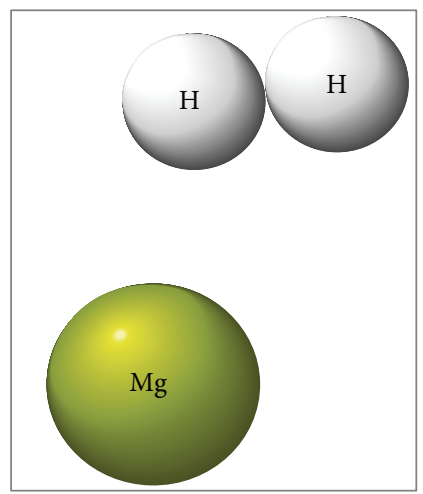

$\mathrm{Mg}-\left(\mathrm{H}_{2}\right)$

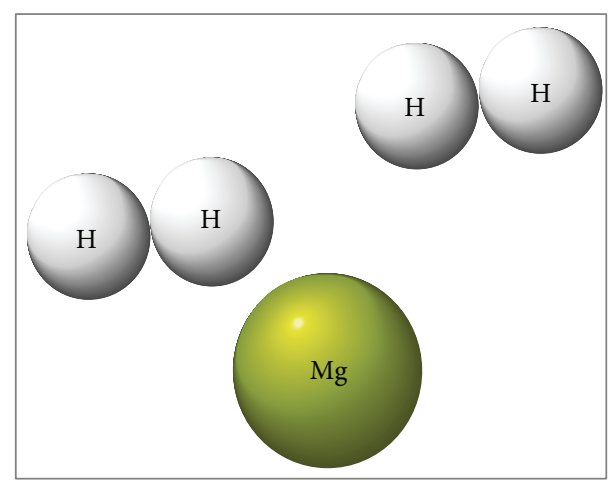

$\operatorname{Mg}-\left(\mathrm{H}_{2}\right)_{2}$

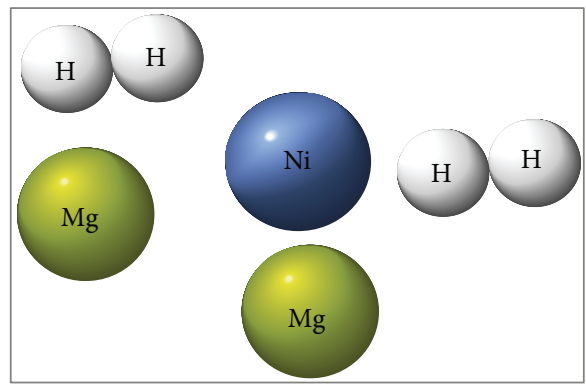

$\mathrm{Mg}_{2} \mathrm{Ni}-\left(\mathrm{H}_{2}\right)_{2}$

FIgUre 6: Optimized geometry of $\mathrm{Mg}-\left(\mathrm{H}_{2}\right)_{n}$ and $\mathrm{Mg}_{2} \mathrm{NiH}_{4}$ hydrides.

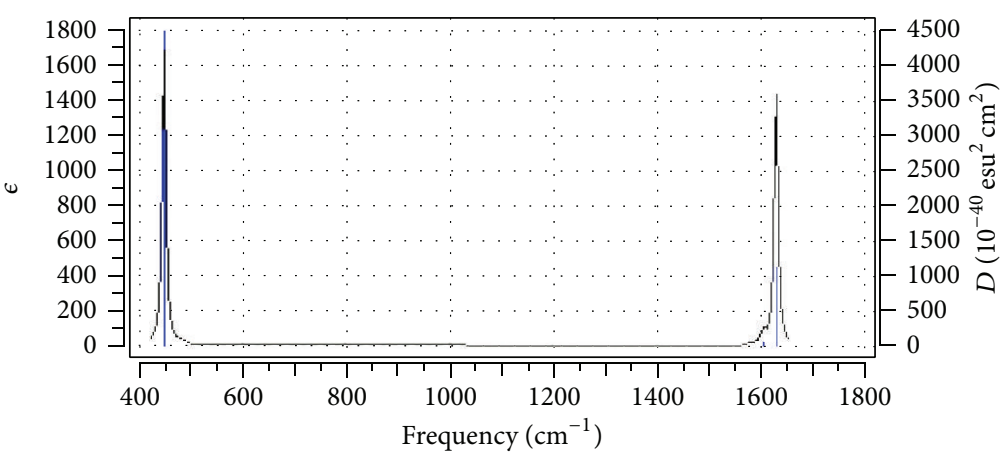

FIGURE 7: Software generated IR spectroscopy of $\mathrm{MgH}_{2}$.

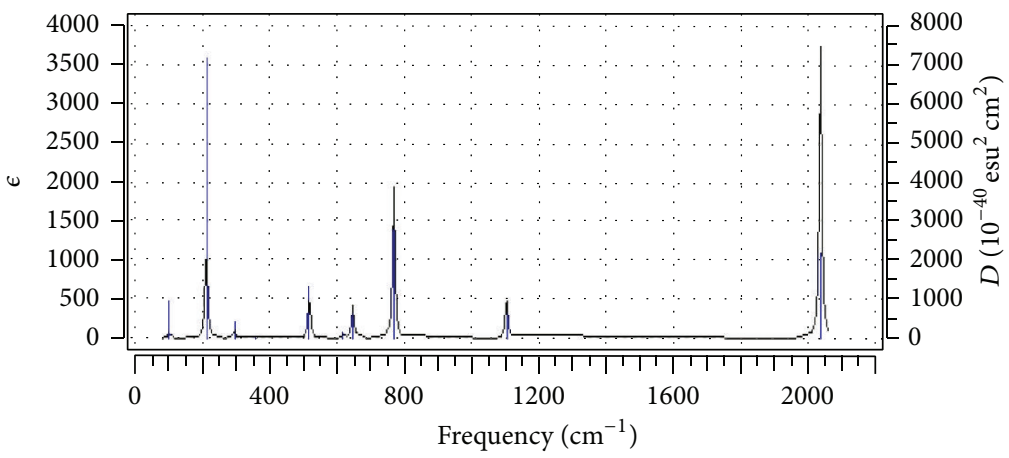

FIGURE 8: Software generated IR spectroscopy of $\mathrm{Mg}_{2} \mathrm{NiH}_{4}$. 
TABLE 1: Hydride clusters descriptors.

\begin{tabular}{lcccc}
\hline Cluster name & $\begin{array}{c}E \\
\mathrm{~kJ} / \mathrm{mol}\end{array}$ & $\begin{array}{c}\eta \\
\mathrm{kJ} / \mathrm{mol}\end{array}$ & $\begin{array}{c}\chi \\
\mathrm{kJ} / \mathrm{mol}\end{array}$ & $\begin{array}{c}\omega \\
\mathrm{kJ} / \mathrm{mol}\end{array}$ \\
\hline $\mathrm{Mg}-\left(\mathrm{H}_{2}\right)$ & $-5.280 \times 10^{5}$ & 86.74 & 911.92 & 605.47 \\
$\mathrm{Mg}-\left(\mathrm{H}_{2}\right)_{2}$ & $-5.311 \times 10^{5}$ & 118.09 & 376.75 & 601.00 \\
$\mathrm{Mg} \mathrm{Ni}_{(}\left(\mathrm{H}_{2}\right)_{2}$ & $-5.015 \times 10^{6}$ & 190.48 & 383.88 & 386.83 \\
\hline
\end{tabular}

E.: total electronic energy, $\eta$ : hardness, $\chi$ : electronegativity, $\omega$ : electrophilicity.

TABLE 2: Energy descriptors of clusters.

\begin{tabular}{lcccc}
\hline Cluster name & $\begin{array}{c}\Delta E_{i} \\
\mathrm{~kJ} / \mathrm{mol}\end{array}$ & $\begin{array}{c}\Delta E_{\mathrm{Hyd}} \\
\mathrm{kJ} / \mathrm{mol}\end{array}$ & $\begin{array}{c}\Delta E_{\text {des }} \\
\mathrm{kJ} / \mathrm{mol}\end{array}$ & $\begin{array}{c}\Delta \omega \\
\mathrm{kJ} / \mathrm{mol}\end{array}$ \\
\hline $\mathrm{Mg}-\left(\mathrm{H}_{2}\right)$ & -76.13 & 76.13 & 79.31 & 212.46 \\
$\mathrm{Mg}-\left(\mathrm{H}_{2}\right)_{2}$ & -43.93 & 87.84 & 78.00 & 104.43 \\
$\mathrm{Mg}_{2} \mathrm{Ni}-\left(\mathrm{H}_{2}\right)_{2}$ & -25.11 & 50.22 & 54.72 & 65.95 \\
\hline
\end{tabular}

$\Delta E_{i}:$ interaction energy, $\Delta E_{\text {ads }}$ : adsorption energy, $\Delta E_{\text {des }}:$ desorption energy, $\Delta \omega$ : reaction electrophilicity.

TABLE 3: Thermodynamics and kinetics descriptors.

\begin{tabular}{lcccc}
\hline Cluster name & $\begin{array}{c}\Delta H_{r} \\
\mathrm{~kJ} / \mathrm{mol}\end{array}$ & $\begin{array}{c}\Delta G_{r} \\
\mathrm{~kJ} / \mathrm{mol}\end{array}$ & $\begin{array}{c}\Delta S_{r} \\
\mathrm{~J} / \mathrm{mol} \cdot \mathrm{K}\end{array}$ & $\begin{array}{c}k \\
\mathrm{~S}^{-1}\end{array}$ \\
\hline $\mathrm{Mg}-\left(\mathrm{H}_{2}\right)$ & -62.90 & -5.64 & -158.18 & $6.0 \times 10^{13}$ \\
$\mathrm{Mg}-\left(\mathrm{H}_{2}\right)_{2}$ & -58.85 & -1.42 & -159.13 & $1.1 \times 10^{13}$ \\
$\mathrm{Mg}_{2} \mathrm{Ni}-\left(\mathrm{H}_{2}\right)_{2}$ & -52.78 & -13.41 & -166 & $1.3 \times 10^{15}$ \\
\hline
\end{tabular}

$\Delta H_{r}$ : reaction enthalpy, $\Delta G_{r}$ : Gibb's free energy, $k$ : rate of adsorption at $303 \mathrm{~K}$.

Different energy parameters have been investigated for $\mathrm{Mg}-\left(\mathrm{H}_{2}\right)_{n}$ and $\mathrm{Mg}_{2} \mathrm{NiH}_{4}$ and shown in Table 2. Interaction energies between hydrogen and metal cluster increase with gradual number of captured hydrogen. Hydrogenation and interaction energies are increasing based on gradual addition of hydrogen. These phenomena correspond to the favorable hydrogenation on metals. Table 2 shows that adsorption energy values are higher than $50 \mathrm{~kJ} / \mathrm{mol}$ and indicate chemisorption range hydrogenation (strongly bonded). According to the calculated data, (Table 2) interaction energy corresponds to the fact that the interaction between metals and hydrogen is electrostatic range. Magnesium shows higher affinity with hydrogen than nickel. Addition of nickel decreases strength of bonding between magnesium and hydrogen. The average desorption energies (Table 2) of the hydrides attribute that desorption may occur at higher condition (temperature, pressure) for the less adsorbed hydrogen and maximum captured hydrogen decompose at low temperature. Predicted hydrogen desoprtion energies (or decomposition energy) of $\mathrm{MgH}_{2}$ and $\mathrm{Mg}_{2} \mathrm{NiH}_{4}$ are $79.31 \mathrm{~kJ} / \mathrm{mol}$ and $54.72 \mathrm{~kJ} / \mathrm{mol}$ which is one of the important concerns for reversible hydrogenated materials and those are close to the calculated desorption energy value of $76 \mathrm{~kJ} / \mathrm{mol}$ (for $\mathrm{MgH}_{2}$ ) by Swart et al., [27]. Reaction electrophilicity values of hydrides are decreasing upon increasing number of hydrogen captured. This phenomenon is very favorable for high hydrogenation [28].
The thermodynamic descriptors of hydride phases such as change of Gibb's free energies $\left(\Delta G_{r}\right)$, enthalpy change $\left(\Delta H_{r}\right)$, and entropy change $\left(\Delta S_{r}\right)$ were computed to ensure the feasibility of hydrogenation on metals surfaces. The negative (-) values of Gibb's free energies $\left(\Delta G_{r}\right)$, shown in Table 3, ensure the favorable hydrogenation phenomenon at room temperature and indicate the impetuous behavior of hydrogenation. DFT predicted values of hydrogenation enthalpy and entropy changes of hydrogenated clusters of $\mathrm{MgH}_{2}$ and $\mathrm{Mg}_{2} \mathrm{NiH}_{4}$ are $-62.90 \mathrm{~kJ} / \mathrm{mol},-158 \mathrm{~J} / \mathrm{mol} \cdot \mathrm{K}$ and $-52.78 \mathrm{~kJ} / \mathrm{mol},-166 \mathrm{~J} / \mathrm{mol} \cdot \mathrm{K}$, respectively, that are close to reversible hydrogen storage materials thermodynamics values of $-40 \mathrm{~kJ} / \mathrm{mol}$ and $-130 \mathrm{~J} / \mathrm{mol} \cdot \mathrm{K}$ [6]. Negative enthalpy $\left(\Delta H_{r}\right)$ of hydrides indicates that the hydrogenation is exothermic. Decreasing trend of entropy corresponds to the limitation of hydrogen movement on surface due to the less degrees of freedom of hydrogen. The reaction constant values are in the order of $\left(A \times 10^{13}\right)$ that attribute to the slow hydrogenation on this materials surface.

\section{Conclusion}

The density functional theory (DFT) study has explained the mechanism of the hydrogenation and the hydrogenation properties of microstructure. Variation of the thermodynamics and energy descriptor values upon increasing captured hydrogen molecules correspond to the promising activities of the hydride microstructure and their feasible hydrogenation properties. Experiment and DFT based investigation demonstrated similar IR frequencies, which confirm the hydride formation of $\mathrm{MgH}_{2}$ and $\mathrm{Mg}_{2} \mathrm{NiH}_{4}$. Isothermal adsorption analysis predicted high hydrogenation capacity which is higher than the stoichiometric capacity of $\mathrm{Mg}_{2} \mathrm{NiH}_{4}(3.6 \mathrm{wt} \%$ hydrogen). Polycrystalline and flower-like interactive rough microstructure is an important material's properties that can be formed in an optimal condition to enhance the hydrogenation.

\section{Conflict of Interests}

The authors declare that there is no conflict of interests regarding the publication of this paper.

\section{Acknowledgments}

The authors acknowledge gratefully the financial support of this study by the FRGS Grant 158-200-092, Malaysia, and the computational facility provided by University of Malaya.

\section{References}

[1] U. Eberle, G. Arnold, and R. von Helmolt, "Hydrogen storage in metal-hydrogen systems and their derivatives," Journal of Power Sources, vol. 154, no. 2, pp. 456-460, 2006.

[2] H. Shao, G. Xin, J. Zheng, X. Li, and E. Akiba, "Nanotechnology in Mg-based materials for hydrogen storage," Nano Energy, vol. 1, no. 4, pp. 590-601, 2012. 
[3] I. P. Jain, C. Lal, and A. Jain, "Hydrogen storage in Mg: a most promising material," International Journal of Hydrogen Energy, vol. 35, no. 10, pp. 5133-5144, 2010.

[4] W.-J. Song, J.-S. Li, T.-B. Zhang et al., "Microstructure and hydrogenation kinetics of $\mathrm{Mg}_{2} \mathrm{Ni}$-based alloys with addition of $\mathrm{Nd}, \mathrm{Zn}$ and Ti," Transactions of Nonferrous Metals Society of China, vol. 23, no. 12, pp. 3677-3684, 2013.

[5] W. Oelerich, T. Klassen, and R. Bormann, "Comparison of the catalytic effects of $\mathrm{V}, \mathrm{V}_{2} \mathrm{O}_{5}, \mathrm{VN}$, and $\mathrm{VC}$ on the hydrogen sorption of nanocrystalline Mg," Journal of Alloys and Compounds, vol. 322, no. 1-2, pp. L5-L9, 2001.

[6] M. A. Salam, S. Sufian, and T. Murugesan, "Catalytic hydrogen adsorption of nano-crystalline hydrotalcite derived mixed oxides," Chemical Engineering Research and Design, vol. 91, no. 12, pp. 2639-2647, 2013.

[7] M. A. Salam, Y. Lwin, and S. Sufian, "Synthesis of nanostructured Ni-Co-Al hydrotalcites and derived mixed oxides," Advanced Materials Research, vol. 626, pp. 173-177, 2013.

[8] S. Kang, S. Karthikeyan, and J. Y. Lee, "Enhancement of the hydrogen storage capacity of $\mathrm{Mg}\left(\mathrm{AlH}_{4}\right)_{2}$ by excess electrons: a DFT study," Physical Chemistry Chemical Physics, vol. 15, no. 4, pp. 1216-1221, 2013.

[9] Y. Liu, L. P. Meng, S. J. Zheng, and S. W. Zhang, "The DFT studies on a novel hydrogen storage material $\mathrm{Mg}_{12} \mathrm{Ni}_{6-x} \mathrm{Cr}_{x}(\mathrm{x}=0,1)$," Applied Mechanics and Materials, vol. 457-458, pp. 181-184, 2014.

[10] M. A. Salam, S. Sufian, and Y. Lwin, "Hydrogen adsorption study on mixed oxides using the density functional theory," Journal of Physics and Chemistry of Solids, vol. 74, no. 4, pp. 558564, 2013

[11] K. W. Wiitala, T. R. Hoye, and C. J. Cramer, "Hybrid density functional methods empirically optimized for the computation of ${ }^{13} \mathrm{C}$ and ${ }^{1} \mathrm{H}$ chemical shifts in chloroform solution," Journal of Chemical Theory and Computation, vol. 2, no. 4, pp. 1085-1092, 2006.

[12] D. Y. Chang, S. Y. Bong, S. N. Young, and S. B. Jong, "Hydriding properties of $\mathrm{Mg}-\mathrm{xNi}$ alloys with different microstructures," Catalysis Today, vol. 120, pp. 276-280, 2007.

[13] M. A. Salam, S. Sufian, and T. Murugesan, "Characterization of nano-crystalline $\mathrm{Mg}$-Ni-Al hydrotalcite derived mixed oxides as hydrogen adsorbent," Materials Chemistry and Physics, vol. 142, no. 1, pp. 213-219, 2013.

[14] W. J. Hehre, L. Radom, P. V. R. Schleyer, and J. Pople, AB Initio Molecular Orbital Theory, John Wiley \& Sons, New York, NY, USA, 1987.

[15] M. J. Frisch, G. W. Trucks, H. B. Schlegel et al., Gaussian 09W, Gaussian Inc, 2009.

[16] R. G. Parr and R. G. Pearson, "Absolute hardness: companion parameter to absolute electronegativity," Journal of the American Chemical Society, vol. 105, no. 26, pp. 7512-7516, 1983.

[17] R. G. Pearson, Chemical Hardness: Applications from Molecules to Solids, Wiley-VCH, Weinheim, Germany, 1997.

[18] M. V. Putz, "Electronegativity: quantum observable," International Journal of Quantum Chemistry, vol. 109, no. 4, pp. 733738, 2009.

[19] K. M. Thomas, "Hydrogen adsorption and storage on porous materials," Catalysis Today, vol. 120, no. 3-4, pp. 389-398, 2007.

[20] Ochterski, Thermochemistry in Gaussian, Gaussian, Inc, Wallingford, Conn, USA, 2000.

[21] W. H. Zachariasen, C. E. Holley, and J. F. Stamper Jr., "Neutron diffraction study of magnesium deuteride," Acta Crystallographica, vol. 16, pp. 352-353, 1963.
[22] J. Zou, H. Sun, X. Zeng, G. Ji, and W. Ding, "Preparation and hydrogen storage properties of $\mathrm{Mg}$-rich $\mathrm{Mg}$-Ni ultrafine particles," Journal of Nanomaterials, vol. 2012, Article ID 592147, 10 pages, 2012.

[23] O. Friedrichs, L. Kolodziejczyk, J. C. Sánchez-López, C. LópezCartés, and A. Fernández, "Synthesis of nanocrystalline $\mathrm{MgH}_{2}$ powder by gas-phase condensation and in situ hydridation: TEM, XPS and XRD study," Journal of Alloys and Compounds, vol. 434-435, pp. 721-724, 2007.

[24] R. J. Sibley and R. A. Alberty, Physical Chemistry, John Wiley \& Sons, New York, NY, USA, 3rd edition, 2001.

[25] X. Wang and L. Andrews, "Infrared spectra of magnesium hydride molecules, complexes, and solid magnesium dihydride," Journal of Physical Chemistry A, vol. 108, no. 52, pp. 1151111520, 2004.

[26] E. N. Koukaras, A. D. Zdetsis, and M. M. Sigalas, "Ab initio study of magnesium and magnesium hydride nanoclusters and nanocrystals: examining optimal structures and compositions for efficient hydrogen storage," Journal of the American Chemical Society, vol. 134, no. 38, pp. 15914-15922, 2012.

[27] I. Swart, A. Filicki, B. Redlich, G. Meijer, B. M. Weckhuysen, and F. M. F. de Groot, "Molecular adsorption of $\mathrm{H}_{2}$ on small cationic nickel clusters," Journal of the American Chemical Society, vol. 192, pp. 2516-2520, 2012.

[28] Q. Zheng, Y. Pivak, L. P. A. Mooij et al., "EXAFS investigation of the destabilization of the $\mathrm{Mg}-\mathrm{Ni}-\mathrm{Ti}(\mathrm{H})$ system," International Journal of Hydrogen Energy, vol. 37, no. 5, pp. 4161-4169, 2012. 

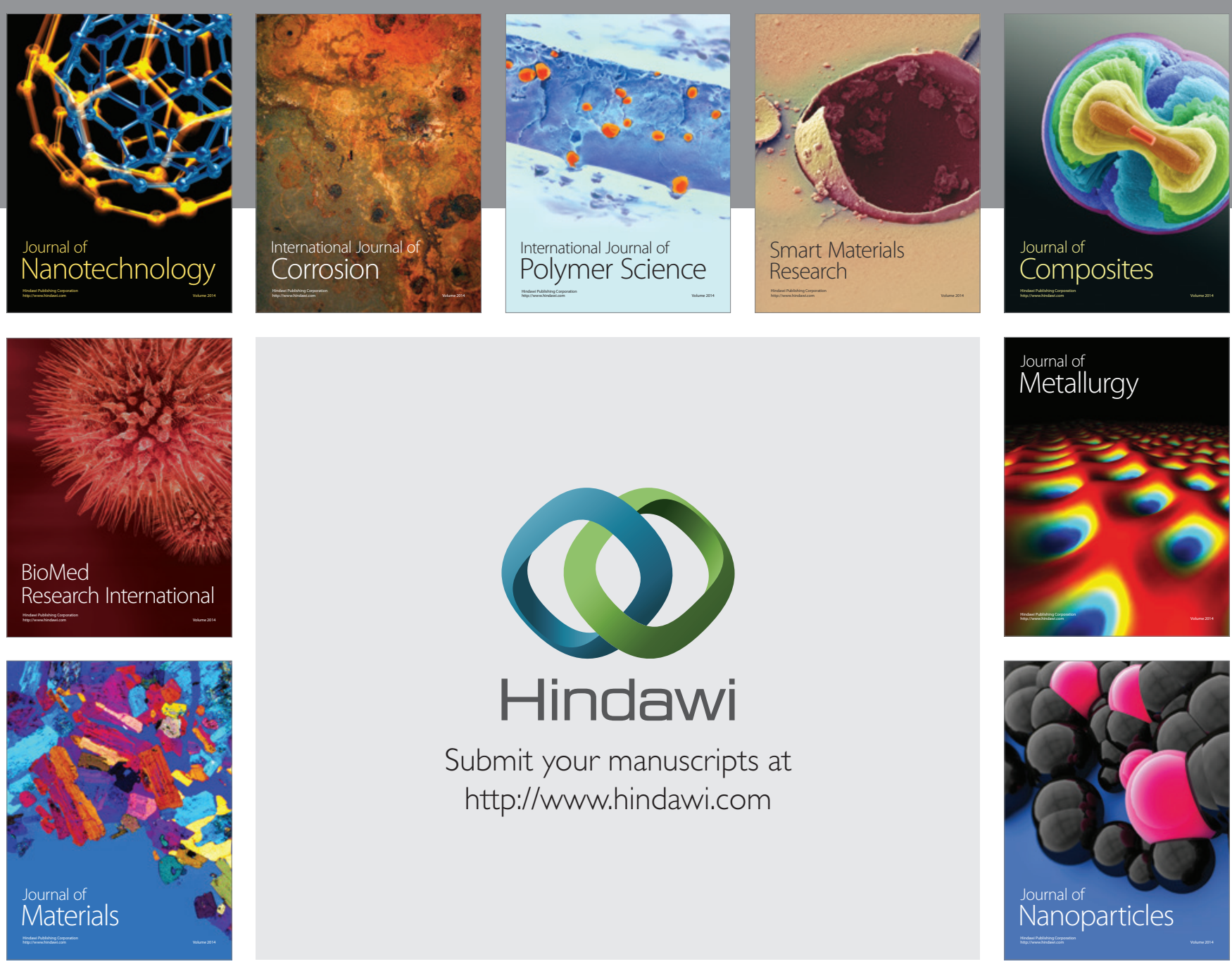

Submit your manuscripts at http://www.hindawi.com
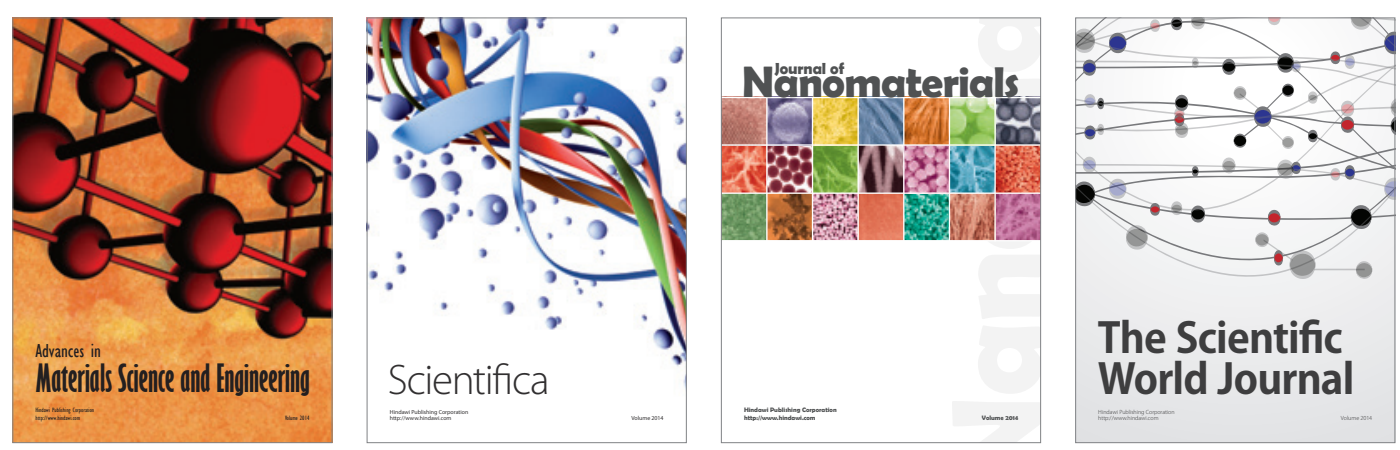

\section{The Scientific World Journal}
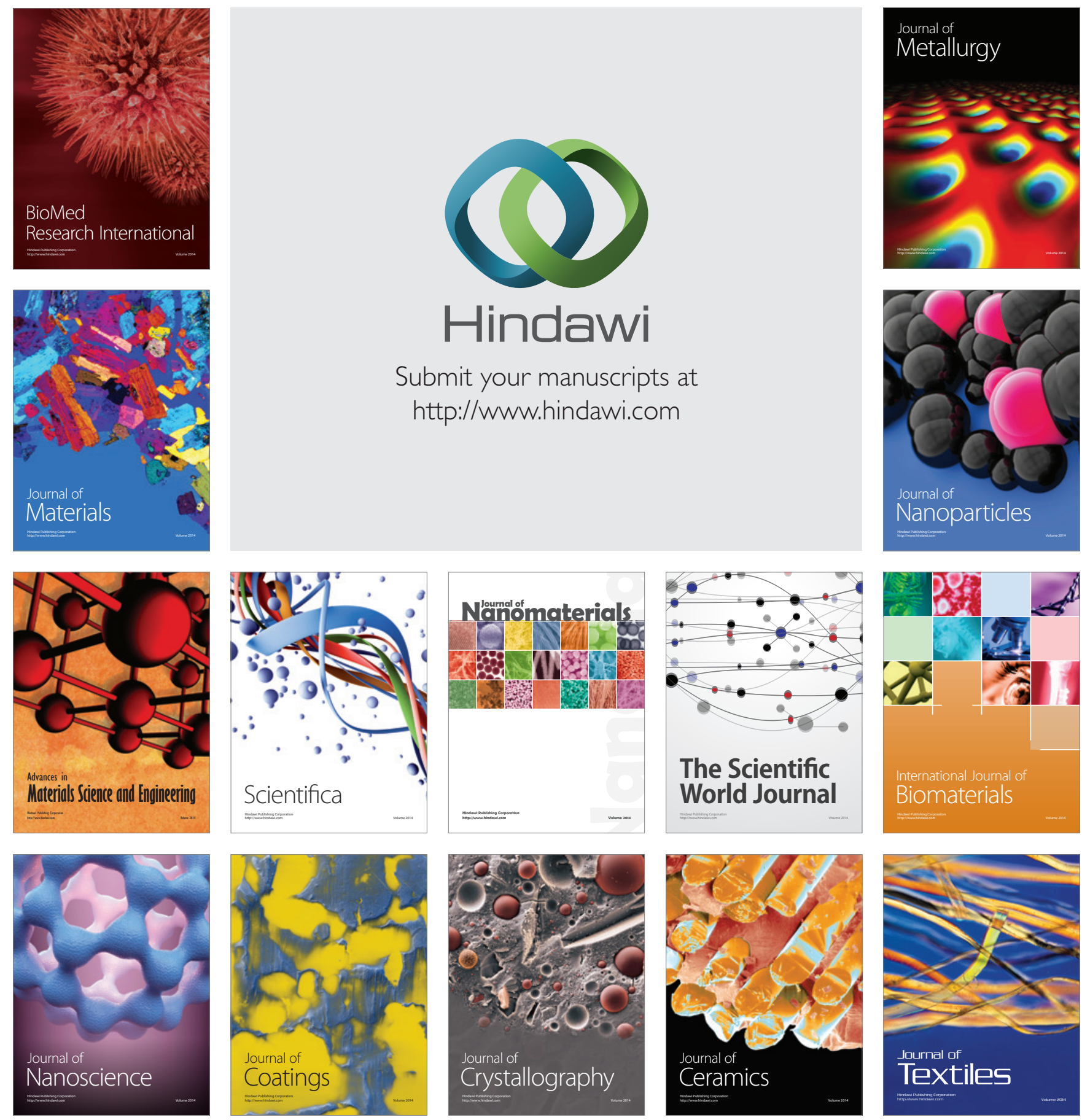